\title{
Responding to the pandemic as a family unit: social impacts of COVID-19 on rural migrants in China and their coping strategies
}

\author{
Shuangshuang Tang (1) ${ }^{1,2} \&$ Xin $\mathrm{Li}^{3 凶}$
}

In 2020, the COVID-19 pandemic has created tremendous chaos in people's daily lives around the world. However, the related social impacts vary across social groups. Compared to people with abundant resources, the more disadvantaged tend to suffer greater negative social impacts from disasters. Although it is a crucial topic, there has been limited research on the social impacts of disastrous epidemics on uninfected people in developing countries. To bridge the gap, this study investigates the social impacts of the spread of COVID-19 on rural migrants and their coping strategies through face-to-face interviews with rural migrants in Nanjing, China. The household perspective is highlighted to explore how rural migrants deal with various threats induced by COVID-19 spread. The study finds that rural migrants suffered from serious social impacts due to COVID-19, especially during the associated lockdown period. Despite some similar impacts, influences of COVID-19 varied among rural migrants at different life-cycle stages, due to variations in human capital, family burdens, role in a household, and ability to find part-time work. Receiving little support from governments and employers, rural migrants tended to adopt household strategies to deal with difficulties related to COVID-19. Within a household, they assisted each other and worked as a unit to maximize resources and reduce risks. Traditional family values were highly praised by rural migrant households during the period. Findings also suggest that both central and local governments need to provide practical aid to this group and to improve the social security system for rural migrants. 


\section{Introduction}

n January 23, 2020 (one day before China's Spring Festival), Wuhan closed the city in order to control the spread of Corona Virus Disease 2019 (COVID-19). By January 25, 30 provinces in China initiated the "level one response" to major public health emergencies, which involved implementation of measures to control the spread of COVID-19 at the strictest level. In the context of lockdown, in urban communities and villages of China, a series of measures were carried out to prevent people from moving freely. Since the society is unequal, the strict control measures may have had different social impacts on different groups in the population. In particular, the severely restricted mobility of the population, either due to the lockdown or to fears of infection, may have deepened the existing gap between populations from rural and urban areas. In China, rural migrants are typically more disadvantaged than urban residents, due to the institutional barrier of the hukou system (residential registration system) and inequality in education, welfare, and social capital (Song et al., 2008; Yue et al., 2013). Thus, it is assumed that rural migrants in China, who were either trapped in their rural hometown or in destination cities during the period of COVID-19 spread that lasted from late January to early March, were more likely to experience risks and uncertainties and fall into difficult situations. In fact, it was reported that around 25 million rural migrants in China were either unemployed or waiting to return to work by the end of February; these migrants suffered sharp reductions in income and reduced job opportunities (International Labour Organization, 2020). In order to deal with the difficulties, rural migrants had to carry out a series of coping strategies in the absence of help from governments and employers.

In the existing research, it is widely accepted that disasters, including natural disasters and disastrous epidemics, are social events, the outcomes of which are associated with pre-existing social inequalities. Research in some western countries has focused on how ethnic people and minorities, who tend to be marginalized, deal with social impacts of disasters and adopt coping strategies that are distinct from those faced by the majority population. Typically, during and after disasters, these people are more likely to lose their incomes and homes (Zottarelli, 2008; Elliott and Paris, 2006), and have more difficulty in recovering from disasters (Peacock et al., 1997; Aptekar, 1990). Despite a body of relevant literature, research gaps remain. First, most studies have been concerned with the impacts of natural disasters (e.g. hurricane and earthquake) on differentiated social groups rather than the impacts of disastrous epidemics. Although a few studies have elaborated the topic by unfolding the impacts on infected people or their caregivers, such as nurses or doctors, the related influences on uninfected people are largely ignored in existing research. However, the risks of infection induced by disastrous epidemic on differentiated people may be different from those due to the direct impacts of natural disasters. In particular, lockdown, movement control, and social distancing associated with disastrous epidemics, however can directly result in negative consequences (i.e. loss of home and income) for the affected groups. Second, although a few COVID-19-related studies have been carried out in China, the differentiated social impacts of disasters and the qualitative nature of coping strategies have been little investigated in China, where the inequalities caused by institutional schemes and social class are obvious. Further, characteristics of Chinese culture, such as Confucian ideology, also give rise to distinct circumstances. Third, it is reported that disadvantaged people tend to take the entire family as a unit when they make decisions and cope with difficulties (Stark and Bloom, 1985). In the face of a severe public crisis such as COVID-19, a household strategy is vital for those who are neglected by the existing welfare system. Particularly among marginalized groups, family is an essential source of support to which individuals turn to relieve their suffering. Previous studies have referred to the importance of social capital in dealing with disasters, but little attention has been paid to this issue from the household perspective. A household approach to crisis is pervasive in China because family values are highly emphasized in traditional Chinese culture (Fei, 1983), but how such an approach affects the coping strategies of disadvantaged groups, such as rural migrants in China, remains underexplored.

Based on face-to-face in-depth interviews with rural migrants, this paper contributes to existing literature by focusing on the social impact of COVID-19 spread on rural migrants and their coping strategies in the Chinese setting. In particular, it emphasizes how household strategy is adopted by rural migrants in China to combat social impacts induced by the COVID-19 pandemic. By focusing on migrant groups in different life stages, the study also elaborates variations among rural migrants in China. This research not only extends theories about social inequalities by analyzing the social impacts of disastrous epidemics (COVID-19 pandemic) on a group of disadvantaged people, but also provides insights on policymaking for vulnerable people during and after disasters.

The remainder of this paper is organized into the following sections: A review of relevant research, a description of the data and research area, and an analysis of social impacts and coping strategies of rural migrant workers in China. The final section presents conclusions based on the study findings.

\section{Literature review}

Inequalities in the social impacts of disasters. A disaster, whether a natural disaster or a disastrous epidemic such as Ebola or severe acute respiratory syndrome (SARS), is a crisis that can result in large-scale damage to people and hinder their recovery. It is acknowledged that disasters are social events that are linked with social processes and differentiated social groups (Peacock et al., 1997). In addition to physical and psychological impacts, disasters can exert social impacts on people, and people adopt various coping strategies to deal with disasters. The social impacts and coping strategies for disasters are determined not only by the event itself, but also by socio-economic features and different conditions under which people face those disasters (Blaikie et al., 1994). That is, social stratification shapes and differentiates the outcomes of disasters. More specifically, social impacts and coping strategies can vary among differentiated groups of people as a result of pre-existing social inequalities. In existing research, the social impacts of disaster are typically found to be worse for marginalized groups.

In many countries, marginalized groups are distinguished from the majority population by race, ethnicity, or class, and they are often poorly integrated into mainstream societies. The majority of marginalized people are working in low-end manual labor sectors with low incomes, and many are employed only part-time or even unemployed (Fothergill et al., 1999; Elliott and Paris, 2006). As a consequence, when a disaster occurs, these groups tend to have insufficient resources and tend to be neglected by authorities, making it impossible for them to minimize the associated negative influences or to recover quickly. In general, marginalized groups in each society vary on the basis of local social, economic, cultural, and political contexts (Che et al., 2020). For instance, in the USA or Western Europe, the term "socially disadvantaged group" often refers to those who are minorities (e.g. Blacks), who lack legal status (e.g. illegal immigrants), or who have specific religious beliefs (e.g. Muslins), while in countries such as China or India, sharp rural-urban divisions and associated institutional 
barriers have made the plight of internal migrants, i.e. rural-tourban migrants, the concern of the public and governments (Che et al., 2020; Rahman, 2020).

Empirical studies have explored the social impacts of disasters on marginalized people, and migrants in particular, through a variety of lenses. First, it is understood that disaster may damage local economies and result in job loss, due to migrations out of the impact zone, relevant financial crises, and disrupted workplaces. Normally, marginalized people have a higher chance of losing their jobs after a disaster because their jobs are not only low-paying, but also relatively unstable, especially when businesses close or move after a disaster (Morrow, 1999). For instance, black workers were more likely to suffer job loss than their white counterparts after Hurricane Katrina (Zottarelli, 2008; Elliott and Paris, 2006), and the frequently changing residence by ethnic group after a hazard is negatively associated with highlevel and stable employment (Zottarelli, 2008). Large disparities between African-Americans and whites are also observed in the loss of full-time employment status after a disastrous storm (Chaganti and Waddell, 2015).

Second, disaster may cause housing instability, including loss of home, resettlement, and moving. Marginalized people may encounter more serious housing problems in the context of a disaster. Dwellings of marginalized people are more likely to sustain greater damage during a disaster because their dwellings are often poorly maintained and located in disadvantaged locations that bear the brunt of the disasters (Morrow, 1999). Meanwhile, low-income people and minorities have more difficulty finding housing after a disaster (Bolin and Stanford, 1998; Bolton et al., 1993). That is probably because the quantity of affordable housing normally shrinks and demand increases in a housing market after a disaster, which could reduce the housing available to the marginalized population, adding to the precarity of their socio-economic situations (Pais and Elliott, 2008; Masozera et al., 2007). Moreover, it is generally easier for landlords to evict low-income tenants as compared to higher-income tenants. As a consequence, lowerincome people have to move more frequently (Haas et al., 1977) and, after a disaster, a large share of them move to local shelters and have no homes to return to (Brodie et al., 2006). Even among homeowners, substantial class disparities in social impacts exist. It is observed that, after a hurricane, low-income homeowners are less likely to return to their pre-disaster homes and need more assistance than affluent homeowners (Elliott and Paris, 2006).

In addition to effects on employment and housing, disasters have other long-lasting influences on disadvantaged groups, making it difficult for these groups to recover. For instance, after natural disasters, ethnic populations are more likely to receive insufficient settlement amounts and insurance payouts, and be left out of distributions by formal aid networks, thereby slowing down the recovery process (Peacock et al., 1997; Aptekar, 1990). After Hurricane Andrew, the recovery from the storm was slower and more difficult for minority populations, which can be explained by limited human capital, inadequate insurance payouts, lack of financial resources, and governmental neglect (Dash et al., 2007). Moreover, marginalized people commonly have difficulty in applying for governmental loans because governmental disaster recovery programs tend to reject applicants who have low incomes and low credit ratings (Masozera et al., 2007). Additionally, during the spread of disastrous epidemics, marginalized people tend to be less aware of the channels through which they can seek assistance and their needs are often ignored (Sastry and Dutta, 2017).

Migrant household strategies. It has been argued that decisions are often not made by an isolated individual, but by the entire household (Stark, 1991). People's planning and decision-making are often made in consideration of family needs and household interactions (Ryan et al., 2009). In line with this, people may adopt strategies to cope with difficulties by taking the entire household as a unit, for taking care of the well-being of individuals within the family, via approaches including reciprocity and affections. The household strategy is particularly pervasive among disadvantaged families, including in migrant populations, since such families typically lack institutional mechanisms to guarantee household benefits and to minimize household risks (Gubhaju and de Jong, 2009). The household strategy approach focuses on social actors in a household and it is a "bottom up" perspective (Wallace, 2002).

Empirical studies have found that household strategies are often used by disadvantaged people to cope with difficulties, including disasters and unemployment. This is especially true for migrants from underdeveloped countries with large rural populations, such as China and India. The informal or disadvantaged status (e.g., the lack of local hukou or belonging to a lower caste) and limited personal capacities (lower educational level and lack of marketable skills) of rural-tourban migrants in these countries can constrain their eligibility to receive public benefits and limit their abilities to combat negative social impacts of disasters. Accordingly, it was reported that, as the COVID-19 pandemic spread, rural migrants in these countries were fast becoming some of the populations subject to the most suffering (Che et al., 2020; Rahman, 2020). They were experiencing severe threats to health, worsened living environments, and poverty.

It is observed that disadvantaged people such as migrants tend to rely on kinship networks when they experience disasters. Although it is argued that extended families are too poorly organized to effectively respond to disasters, disadvantaged people are inclined to depend on family members' help rather than help from others (Clifford, 1956). Among the disadvantaged, support from informal kinship networks is frequently used to respond to a disaster (Messias et al., 2012; Richards et al., 2015). In addition to its use in coping with disasters, a household strategy is also adopted by disadvantaged people when they encounter economic recession and unemployment. For instance, kinship networks are an important means for migrants to find employment opportunities (Sacchetto and Vianello, 2015). Refugees also turn to family members to help them find jobstypically unskilled and low-paying-in an unfamiliar environment (Ray, 2018). In order to deal with uncertainties, migrants tend to reinforce their kinship networks and fulfill family obligations to other family members within a household (Ryan, 2004). In the context of economic recession, childcare is often arranged by two working parents in the form of work shifts, and extended family members also provide childcare and housing to support each other (Pratt and Hanson, 1991). Informal and domestic work also play a role in the arrangement of work practices in a disadvantaged family (Pahl, 1984; Mingione, 1994).

Moreover, compared to other disadvantaged groups, migrant families often adopt a split-household strategy because they can benefit from the migrant's earnings in the destination while maintaining economic and social resources in the hometown (Fan and Li, 2020). Despite living in destinations for long periods, many migrants still maintain links with their origins and hold open the possibility of return (Mberu et al., 2013). In Britain, Polish migrants take into account both economic and emotional factors when they consider whether to separate or reunite family members (Ryan and Sales, 2013). Household strategies are also found in Italy among Ukrainian grandmothers who support their grandchildren by sending back remittances (Marchetti and Venturini, 2013). 
In China, migrant families also adopt a household strategy for combating crisis. Family in China has been treated as the basic unit for coping with crises or threats, and the underdeveloped welfare system in China has further enhanced the importance of family for individuals. Therefore, mutual assistance within the family are common practices. For instance, a household strategy is applied by migrants when deciding whether to bring children to cities or leave them behind. Constrained by high living costs in cities and difficulties accessing local public schools, migrant parents often send children back to the origin under the care of grandparents, or arrange to have one parent supervise the children's schooling in the hometown, while the other one continues to work outside to support the family financially (Unger and Siu, 2019). Grandparents also engage in household strategies in that they provide childcare and undertake domestic work to support their migrant children (Tang, 2020). Cultural traditions, including patricentric thinking and filial piety, have dominated familial decision-making and the functioning of household strategy (Lee, 2015; Qi, 2018). For instance, patricentric thinking, that is, an emphasis on the benefits and responsibilities of sons for family development, has led to gender differences in the familial domain and made males both the beneficiaries of family assets and the major bearers of family obligations (Qi, 2018). Although it is true that gender equality is slowly increasing in contemporary China, many rural families still subscribe to patricentric thinking, which directly affects interactions between parents and children, between siblings and between spouses. For instance, in a heterosexual married couple, the male is regarded as the major provider for the family, while the female is considered to be responsible for domestic activities. Also, notions of filial piety and family cohesion, which emphasize collectivism and the obedience of junior family members to senior members, tend to increase the willingness (or decrease the resistance) of individuals to sacrifice their own benefits for the welfare of the family (Lee, 2015). Therefore, in the context of the spread of the COVID-19 pandemic, traditional family values in China are very likely to impact an individual's approach to cope with risks and disasters, which may make their response patterns distinct from those of their counterparts in other countries and cultures.

Social vulnerability and rural migrants in China. Social vulnerability, normally measured by individual characteristics such as age, race, gender, occupation, income, and citizenship status, is a product of social inequalities that influence the ability to respond to various types of disasters (Cutter et al., 2003; Blaikie et al., 1994; Stanturf et al., 2015). Due to the inequalities in resources, some people have a higher vulnerability to disasters and greater difficulty recovering from disasters (Durant, 2011).

In the Chinese context, rural migrants are often considered vulnerable people when they are in urban areas. Since the mid1980 s, vast numbers of laborers have been migrating from rural hometowns to cities in pursuit of employment opportunities. Despite working and living in cities, the so-called rural migrants often encounter unequal treatment and fall into vulnerable situations. First, the working conditions of rural migrants are normally disadvantaged. Due to the hukou system, rural migrants who hold rural hukou are likely to be excluded from some urban industries and from urban social welfare programs (Wong et al., 2007). For them, employment in manual, private or informal sectors is prevalent. In addition, they are inclined to encounter forms of discrimination in the urban labor market, such as lower wages, delays in wage payment, long working hours and unwritten contracts (Li, 2010; Demurger et al., 2009). The urban labor market is highly segregated (Chan et al., 1999). Due to limited human capital caused by inequalities in education, rural migrants tend to engage in low-end manual work and the job mobility of this social group remains very low (Wong et al., 2007). This further results in significant wage differences from their urban counterparts (Zhang et al., 2016; Cai and Du, 2011).

Second, rural migrants tend to encounter housing problems in cities. Due to the hukou system, rural migrants are excluded from urban housing welfare, including government-subsidized affordable housing (Wang and Murie, 2000). The urban housing sector only offers limited choices for rural migrants (Wu, 2002). In the urban housing market, available housing for rural migrants is quite scarce and this group typically takes low-skilled and lowincome jobs. As a consequence, the majority of rural migrants cannot afford to rent good-quality private housing (Wong et al., 2007). Employer-provided dormitories and housing in old neighborhoods or urban villages are major sources of housing for rural migrants (Wu, 2002; Li and Duda, 2010). These living places usually have poor living standards, such as crowded living spaces, inadequate facilities, and lack of security and public community space (Song et al., 2008). In addition, the residential areas of rural migrants are often isolated from those of urban residents (Zhu, 2016), resulting in the creation of a residential "invisible wall" between the host society and rural migrant workers in cities (Chan and Buckingham, 2008).

Third, rural migrant workers usually have limited social security and medical benefits. Due to the hukou system, rural migrants have long been excluded from urban social security systems such as pension benefits, medical insurance, and unemployment insurance. Despite reforms of social security programs by some local governments in recent decades, employers still tend to pay their rural migrant employees only a low level of benefits or none at all (Wang, 2011), which means that rural migrants can benefit only minimally from social insurance in cities. More generally, the coverage of urban welfare and insurance programs is highly selective (Huang and Guo, 2017) and varies among people with different human capital and occupational status (Qin et al., 2015). In Chinese cities, a large number of rural migrants are employed in unstable jobs in the informal sector, where their social security rights are usually not protected. Therefore, the participation rate of rural migrants in urban insurance programs is much lower than that of their urban counterparts (Wong et al., 2007).

To summarize, although studies have analyzed the social impacts of natural disasters on disadvantaged people in the USA, Africa, and elsewhere, little attention has been paid to the social impacts of disastrous epidemics on disadvantaged people in China in particular. Additionally, the indirect consequences of disastrous epidemics on disadvantaged people rather than infected people has been little explored. Moreover, since disadvantaged people tend to consider the entire family as a unit when they deal with difficulties, the household perspective needs to be highlighted. To bridge these gaps in existing research, this paper investigates the social impacts of the spread of COVID-19 on rural migrants and their coping strategies in the Chinese setting.

Study area and data. Nanjing is adopted as the study area of this paper. Nanjing, located in the eastern coastal region of China, is the capital of Jiangsu province and the sub-center of Yangtze River Delta. Due to its fast-growing economy, Nanjing has become a developed city, attracting a considerable number of migrants from rural areas inside and outside Jiangsu province. In 2018, Nanjing had 8.44 million permanent residents, of which migrants accounted for $\sim 20$ per cent. In addition, unlike manufacturing-based cities, the gross domestic product (GDP) of Nanjing's service sector accounted for around 60 per cent of the 
total GDP. These statistics indicate that Nanjing not only accommodates numerous rural migrants, but also attracts rural migrants engaged in diversified sectors. Thus, Nanjing is an ideal city to investigate the thoughts and behaviors of rural migrants.

On January 24 (just one day after the lockdown of Wuhan), Nanjing initiated a "level one response" to control the spread of COVID-19. Since then, Nanjing has carried out a series of measures, including the shutoff of large-scale activities, the closure of public facilities and parks, strict health quarantine, disinfection management of public spaces, and strict control of urban communities. Due to the strict measures, a number of workplaces where rural migrants tend to work, including factories, restaurants, and shops, were closed. In addition, many rural migrants were trapped in their rural hometowns for one or several months because of the lockdown of villages and the strict control of intercity traffic. Moreover, despite the transfer from "level one response" to "level two response" on February 24 in Nanjing, economic and human activities had not yet recovered. That is to say, rural migrants were affected for longer than one month, even though some of them did not return to their home villages.

Research data and materials for this study are interspersed with face-to-face in-depth interviews conducted with rural migrants working and living in Nanjing for at least half of the year. Because the COVID-19 control measures have gradually eased and many rural migrants have returned to work since March, the interviews were carried out from April to July. Finally, we interviewed 29 rural migrants. The participants were recruited through a variety of channels, including local survey associations, snowballing and the authors' own networks. Since this research was designed to display coping strategies of rural migrants in different life stages in the context of COVID-19, age, gender, marital status, occupation, and rural origins were considered when recruiting the respondents. The age of participants in our interviews ranged from 20 to 60 years. Fourteen participants were female, which accounted for almost 50 per cent of the total participants. Among the respondents, 14 were single and most of them were younger than 30 . Fifteen were married, who were mainly middle aged or older and had one or more children. Specifically, seven participants were younger migrants with young children and eight were older migrants with adult children. We mainly focused on participants who work in certain labor sectors, such as construction, manufacturing, and services. The occupation selection of respondents refers to the report from the 2019 Rural Migrants' Survey conducted by the National Bureau of Statistics (National Bureau of Statistics of the People's Republic of China, 2020). The majority of these occupations are low-end manual labor, a sector that has undergone serious disruption during the COVID-19 pandemic, due to social distancing, movement controls, and public concerns about transmission of the virus. These measures and public perceptions had direct impacts on the industries in which our respondents work. As a result, rural migrant workers became one of the social groups in China that suffered the most during the pandemic (Che et al., 2020; International Labour Organization, 2020).

All of the interviews were conducted face-to-face, using a semistructured interview schedule. Interview topics mainly included the socio-economic backgrounds of respondents (including their employment, income, and social interactions within and outside their families), their experiences and coping strategies before, during and after the period of COVID-19 spread, and the impacts of the COVID-19 pandemic on their lives. The interviews employed a life narrative methodology (Andrews et al., 2006), which allows each participant to state their views and experiences before, during, and after the spread of COVID-19. Each participant not only talked about their personal experiences, but also told the stories of their entire families during the period.
Each interview lasted for one to two hours. All interviews were audio recorded and subsequently transcribed verbatim, enabling content analysis of the transcription. To guarantee the anonymity of respondents in the analysis, the quotations are accompanied by gender, age, and a fictitious name.

Social impact and coping strategy. During and after the spread of COVID-19, Chinese governments have been inclined to provide aid to enterprises and households below the local poverty level. Nevertheless, the current social welfare system cannot fully provide for all needs, including the needs of rural migrants dealing with disasters such as COVID-19. Rural migrants are typically neither eligible for urban welfare programs, as they have no local hukou or insurance-covered formal jobs in destination cities, nor qualified for related home village assistance, since their incomes are normally above the rural poverty level in their hometowns. As a consequence, despite experiencing difficult times, they must rely on themselves to a large extent.

Previous studies show that disadvantaged people tend to consider benefits to the household when they make decisions in response to challenges, in order to maximize resources and avoid risks (Stark and Bloom, 1985). Therefore, it is assumed that disadvantaged people will adopt household strategies when encountering disasters. In the Chinese setting, the household strategy may be pervasively adopted among rural migrants because the Confucian ideology that is embedded in traditional Chinese culture praises family harmony highly. Following this ideology, family is the basic unit of society. A person is not only an individual, but also a member of a family (Wong and Ahuvia, 1998). For an individual, family is essential to survival and achievement (Cao et al., 2011). Supporting family members is a moral obligation and an aspect of personal integrity. When disasters occur, it is possible that rural migrants have a sense of family duty and solidarity. Thus, in this paper, the household perspective is highlighted to investigate the coping strategies of rural migrants in the Chinese setting.

Social impacts and coping strategies may vary among rural migrants at different stages of the life-cycle, probably due to differences in human and social resources, roles in a household and other capabilities. In this paper, we attend to the experiences of participants at different life-cycle stages. Since marriage and child-rearing are important household events and tasks across the life-courses of rural migrants that significantly influence their decisions (Fan, 2009), rural migrants can be categorized into three groups, including single migrants, younger migrant couples with young children and older migrant couples with adult children. In the paper, the participants' narratives were organized based on this classification. The analysis of participants' narratives enables a comprehensive understanding of the experiences of rural migrants at different life-cycle stages during the period of COVID-19 spread.

Single migrants: children under one "roof". The outbreak of the COVID-19 pandemic had direct influences on the job opportunities and incomes of rural migrants. For younger generations of rural migrants, it not only resulted in severe economic constraints, but also caused severe disruptions to their housing situations and financial conditions. Given the absence of social welfare assistance and employers' subsidies, the younger generation, especially migrants who were in their 20 s and had limited savings, had to rely on family members such as parents and siblings to live through these difficulties.

In China, rural migrants normally get married at an earlier age than their urban peers. Most single participants in this study are in their 20s. The major social impact of COVID-19 on singles is 
related to their employment. Most single respondents reported that their income dropped sharply during the period of COVID19 spread. Due to the strict controls in the city, many workplaces of young rural migrants were forced to shut down for several months. Although those workplaces were gradually reopened after the strict movement controls were relaxed, business was worse than before because most customers avoided going to central public spaces such as restaurants and shops. Meanwhile, orders from factories declined significantly due to the decrease in demand in the market. At the same time, due to the lockdown of villages and strict control of intercity traffic, a number of rural migrants were trapped in their hometowns for several months. Without private cars, most of them had to wait for public transport to resume, which occurred after roads were reopened to private cars. They were thus unable to return to work, even after their workplaces re-opened. As a result, their earnings largely declined. The majority of them had basic wages or no wages, and some of them even lost their jobs due to cost cutting by their employers.

"We are normally quite busy during the Spring Festival, but most customers canceled their reservations this year. We only received very few customers each day. At that time, every day the work was cleaning the restaurant...In early February, the restaurant was closed. When it reopened in April, some of our staff were not told that they could return to work." (Mr. Xie, waiter, age 24)

The negative influences of COVID-19 on single migrants' employment have extended into their other life domains. First, they were at risk of being homeless in urban destinations. This situation is different from the one that occurs after natural disasters, when high housing demand and sharp shrinkage of housing resources creates a gap between supply and demand (Pais and Elliott, 2008; Masozera et al., 2007). During and after the spread of COVID-19 in China, there have been sufficient housing resources to meet the needs of migrants, but some single rural migrants have not been able to afford the rents or continue living in former employer-provided dormitories due to shrinking earnings and job loss. Compared to older migrants, single rural migrants are more likely to have unstable jobs and little savings, which exacerbates their instabilities. The situation becomes more serious when encountering a disaster such as COVID-19. Consequently, some of them had to move out of their former "decent homes" to temporary living places with worse living conditions.

"I waited for my salary to pay my rent, but I did not get the salary. The landlord called the police and kicked me out...I finally found a job delivering take-out food, and they provided a dormitory for me to live in temporarily." (Mr. Xie, deliveryman, age 24)

"I used to live in the dormitory of a hotel. Due to the virus, the hotel had little business, so they let me go. I had to look for a short-term hostel to stay in.” (Mr. Xu, waiter, age 33)

Second, the group of single respondents were at greater financial risks than other migrant groups. Young and single rural migrants normally earn little and have negligible savings, but they tend to spend a lot on purchasing fancy goods (e.g. designer clothes and famous brand cosmetics) like their urban peers. This is probably because they are influenced by modern media, and a large share of them work in the service industry, enabling them to have more encounters with urban culture (Tang et al., 2020). To meet their demands for consumption and to make ends meet, they take out loans from online platform credit companies such as huabei, which they are normally able to pay off monthly.
However, their jobs were seriously affected by COVID-19, resulting in salary suspension, shrinking salaries, or job loss. Hence, some of them had no capacity to pay off their loans, causing tremendous mental stress.

"When I have income, I can pay off the loans each month. But this year, I stayed at my rural home and had no salary for three months, so I cannot afford to pay off my loans...I felt quite stressed because huabei called me to tell me to pay off the loans constantly and I had to pay the increasing interest if I delayed." (Miss Wang, make-up assistant, age 26)

In order to deal with the chaos associated with COVID-19, single migrant respondents adopted various strategies. For them, their parents' home functioned as a "roof," sheltering them from the chaos induced by the pandemic. In light of traditional Chinese culture, unmarried migrants are still considered children under the "roof" of their parents' home. This means they are cared for and protected by their parents and siblings. Thus, kinship networks typically played an important role during the crisis. Those trapped in rural hometowns normally had their basic needs, such as food, provided for by their parents. Hence, during the period of lockdown, they did not need to worry about their survival in home villages. In addition to obtaining basic necessities from their parents in home villages, many single migrant respondents reported that their family cohesion was enhanced during the period. First, they perceived the fact of being trapped at home for several months as a chance for them to enjoy a family reunion after years of family separation that they had undergone to make a living in cities. Second, the main family concern during the period (from late January to early March) had been how this pandemic would affect the health and economic situations of family members. Since mutual reliance among family members was the major and sometimes only strategy that they could rely on during the outbreak, family bonds were strengthened.

Meanwhile, in addition to receiving assistance in home villages, those who had siblings and returned to cities during the period of COVID-19 spread found their siblings willing to help them. As newcomers, young rural migrants tend to move to cities where their siblings or relatives live. They also pay particular attention to kinship networks in their daily lives. In this way, they can rely on kinship networks to somewhat offset the insufficiency of social capital in unfamiliar surroundings and to combat difficulties caused by unstable income and inadequate social security in cities. Also, among most rural migrants, affection among siblings is highly praised, which is influenced by the strong family values embedded in Confucian ideology. Therefore, younger brothers and sisters respect and support their elder siblings. In the context of the spread of COVID-19 in China, kinship support played an especially crucial role in coping with difficulties for single migrants. In addition, related challenges of COVID-19 motivated many single migrants to relocate to cities that are closer to their parents or where their siblings or relatives live. Both single migrants and their family members believe that single migrants can cope with difficulties more easily under the one "roof" of the family because they can receive support from their parents and siblings.

"My older sister was married. She bought an apartment and settled down in Nanjing. When I returned to work from our hometown this year, I visited my sister's home once a week. My sister said that I can live with her if I have no place to stay.” (Miss Qi, shop assistant, age 27)

"My older sister lives in Nanjing. She treats me like my halfmother. When she heard that I cannot pay off my loans 
because of my salary reduction, she gave me the money." (Miss Wang, make-up assistant, age 26)

"I used to work in Chongqing, but due to the virus, my parents have encouraged me to work in Nanjing because it is much closer to my rural hometown." (Mr. Shi, waiter, age 20)

During the period of COVID-19 spread, single rural migrants were not only the recipients of help from their parents and elder siblings; as the young labor force in their families, they also supported their parents and helped them with difficulties. Compared to their parents, single rural migrants are normally better-educated and can more easily access information through social media. This enables them to offer help to their parents during difficult times, including through information and instrumental help. Moreover, since their parents also experienced financial loss due to COVID-19, some single migrants even provided financial support. By assisting each other, family members worked as a unit to overcome the disaster.

"During the period of strict control, it was really hard to buy a mask. But I know some friends who have mask resources and I bought some for my parents who were in our hometown...I also told them how to protect themselves." (Mr. Yang, factory worker, age 27)

"My parents are poorly educated, so I am responsible for the expenses of my family. During the period of virus spread, I controlled the expenses and avoided unnecessary consumption." (Mr. Gao, chef, age 23)

"My parents have a little butcher's shop. Because of the virus, their business is bad. Hence, I often use my salary to buy some food to share their financial burdens." (Miss Li, shop assistant, age 20)

Younger migrant couples with young children: burden-sharing among spouses and support from elder parents. As with the single migrants discussed above, for young migrant couples, the major hazards induced by COVID-19 are job loss and reduced income. However, couples' situations are more complicated than those of singles because couples have children to raise and mortgages to pay. Therefore, younger migrant couples have to rearrange the roles of a husband and wife, and some of them even have to rely on assistance from their parents to cope with the COVID-19 pandemic.

During the interviews, we found that most young migrant couples earn higher salaries than single rural migrants due to work experience and qualifications. As skilled workers, they tended to retain their jobs during the period of COVID-19 spread, but their earnings declined sharply. Many participants mentioned that a sharp decline in earnings caused them serious stress and unease. First, they usually bear heavy family burdens, especially their expenses related to their children. Second, despite working in cities for a long time, they are still disadvantaged due to institutional barriers and limited resources. Therefore, when COVID-19 occurs, they are inclined to feel vulnerable and helpless in cities.

"Due to the virus, I had no salary for two months. I felt quite stressed those days because I have two kids; one is four and the other is two. And I have the mortgage on my apartment. I have to earn money." (Mr. Li, office worker, aged 41)
"The restaurant was closed for three months. I had no salary if I did not work. My wife also had no salary. I felt very stressed. I could not stay at home and wait." (Mr. He, chef, aged 31)

In addition to the impacts on salaries, COVID-19 also influences the family plans of younger migrant couples. After having children and working in cities for a period of time, most young migrant couples begin to think about long-term household plans, such as children's education, buying a house, and where they might want to settle. However, for rural migrants, institutional barriers and low human capital typically lead to unstable working and living conditions in cities (Lu and Zhou, 2008; Qian and Li, 2013). The sudden spread of COVID-19 tended to change their former plans because it brought about more uncertainties. As a consequence, young migrant couples had to delay or modify their visions for the near future to reduce risks.

"We planned to purchase an apartment in suburban Nanjing, but now we have to delay the plan because we are uncertain about our jobs in the future. If we lose our jobs, we cannot afford the housing loans." (Mrs. Zhang, hotel assistant, age 34)

"My son is five. He has to go to primary school in the near future. We intended to purchase an apartment in Nanjing for his education, but it would cause us too much stress now. Probably, we will return to the county, near our rural hometown, to settle down, and my son can go to a good primary school there." (Mrs. Zhong, waitress, age 28)

Compared to singles, young migrant couples had greater family burdens and adopted different strategies to deal with difficulties. They tried their best to increase income by seeking part-time jobs. They also rearranged the division of labor in their households and controlled costs with the help of family members inside the household. As opposed to staying at home and waiting for their workplaces to reopen, younger migrant couples more often actively searched for new job opportunities. Nevertheless, due to the difficulty of finding stable jobs, they tended to search for parttime jobs during the period of COVID-19 spread, often with the goal of simply being able to feed their families. There was a clear notion of gender difference reflected in ideas of who within the family should continue to work during the period. Normally, the arrangement followed the patricentric notion that husbands should work outside so that the family can cope with financial difficulties, whereas wives should stay at home to care for their young children. The shutdown of shops and restaurants during the period led to a sharp increase in delivery services and labor in this sector was in great demand, which helped to absorb redundant migrant labor from closed shops and factories. In addition, online platforms now make it easier to access part-time job opportunities than it was in the past. Male and married migrants were able to find part-time jobs and obtain daily pay in delivery-related sectors. Some of them even took two jobs to make a living. Despite low wages, these jobs helped young migrant couples to make it through the most difficult times.

"When the restaurant was closed, I delivered take-out food. The wage is low, but it can cover the basic living costs of my family.” (Mr. He, chef, age 31)

"I found two jobs through internet: one is to deliver takeout food and the other is to clean windows, airconditioning systems, and range hoods." (Mr. Wang, cleaner, age 41) 
In addition to searching for temporary jobs to deal with shrinking salaries, younger migrant couples control their expenses. They largely reduced the recreation costs and expenses on consumer goods. Moreover, some of younger migrant couples plan to find stable jobs in the future. In urban China, most rural migrants are employed in private and informal workplaces where the employers tend to offer a low level of social insurance or none at all, in order to limit costs (Wang, 2011). In the past, rural migrants accepted higher salaries in lieu of social insurance, but during the period of COVID-19 spread, their basic salaries and welfares could not be guaranteed. Consequently, they began to think more about the importance of stability for their families. Nevertheless, the urban labor market is segregated (Chan et al., 1999) and it is still difficult for them to find a stable job.

"When we had no salary, we only bought food. In order to reduce expenses, we didn't buy other things...I want to find a more stable job in a restaurant run by the government. At least they can provide basic salary and welfare...but this kind of job is hard to find." (Mr. He, chef, aged 31)

While younger migrant couples make their own efforts to cope with difficulties, they also receive help from their parents. The major form of support from parents is care for young children. Rural migrants tend to work overtime and are low-paid. In addition, due to institutional barriers, migrant children are normally unable to access local public schools in cities (Huang et al., 2020). Although the problems of "left-behind" children have become obvious and the relationship between parents and children may be affected negatively (Unger and Siu, 2019), many younger migrant couples have to leave their children behind in the countryside, especially in difficult times. The responsibility of caring for the children is thus turned over to the children's grandparents in the home village.

"Now, my mother helps me care for my son in our rural
hometown. Bringing my son to Nanjing would increase our
living costs, and due to the requirements of my job, I have
no time to look after him...I gave money to my mother, but
she didn't use it and she returned it to me. She knows we
are now facing difficulties in the city." (Mrs. Wang, hotel
assistant, age 34)

"My mother now cares for my two children in our hometown. I telephone them twice a week. Without children, I can live in a free dormitory to save money." (Mr. Yang, gatekeeper, age 30)

Some parents of the younger migrant couples would join to provide childcare for their grandchildren. They have to leave their familiar surroundings and live with their sons or daughters in crowded and shabby living spaces in old urban neighborhoods or urban villages. In addition to childcare, parents also take up domestic work like cooking and cleaning at home to ease the heavy burdens on younger migrant couples.

"My husband is quite busy. I usually work until very late and I have to work on the weekends. My mother-in-law helps us in Nanjing by looking after our son." (Mrs. Zhong, waitress, age 28)

Instead of receiving remittances from children, some parents provide younger migrant couples financial support, even if the parents are in marginalized conditions themselves. In general, in traditional Chinese culture, Confucian ideology praises family values. When encountering disasters, the sense of solidarity appears to become stronger. In their arrangement of household labors, family members of rural migrants observed traditional distinctions between male and female roles, and between the roles of young couples and their parents.

Older migrant couples having adult children: maintaining a precarious life. Compared to the younger generation, older rural migrants typically have more years of working and personal experiences. Nevertheless, in terms of the labor market, they have relatively low levels of human capital, and they typically perform manual labor in the construction industry or work as cleaners or maids in cities. As with rural migrants in other stages of the lifecycle, their jobs have been seriously impacted by COVID-19. Construction sites in cities were shut down for several months. In the service sector, a number of families fired their maids and nannies because they were worried about being infected. In addition, compared to the younger cohort, older rural migrants are not familiar with searching for jobs through online platforms. As a result, most of them stayed at home with little or no earnings during the period of COVID-19 spread. They were likely to suffer more than the younger generation.

"I used to work for three families, but due to the virus, two of them did not let me continue. Now I only work three hours each day...I have been in the market for a new job, waiting to find one, but I haven't found one yet." (Mrs. Shi, hourly maid, age 53)

"I stayed in Nanjing and didn't return to my hometown. I kept my job. But my husband's work was seriously affected. He has two jobs, one delivering goods from a furniture store and another decorating apartments. But due to the virus, he did not work for two months and had no wages." (Mrs. Fang, gatekeeper, age 44)

During the period of COVID-19 spread, older migrant couples not only experienced sharp reductions in incomes, but also faced stress caused by significant financial obligations. It is thought that older migrant couples encounter fewer financial difficulties because they normally retain a strong notion for saving more and spending less in preparation for family crisis resulted from sickness or unemployment, due to the absence of associated social welfare supports. Nevertheless, most of the older migrants still bear heavy burdens. Mainly, these are of two kinds. First, they may still need to pay the living expenses of their adult children. In China, children of rural migrants tend to obtain a lower level of education than their urban peers, and have difficulty securing white-collar jobs with good pay in cities. Thus, in order to reduce costs, many unmarried adult migrants in cities live with their parents, who cover the living costs of the entire household. Moreover, because their offspring are low paid, some parents even provide money to support them. Second, older migrants also need to pay off loans for the marriage of their children, especially their sons. In the minds of many Chinese parents who hold traditional attitudes, parents are obligated to make the preparations for their child's wedding. This means that they need to cover not only the cost of the wedding itself, but also purchase an apartment and a car. It is common that parents of the groom offer housing and wedding gifts, whereas the bride's family provides cars and furniture. This all costs a lot for older migrant couples, and they normally use up most or all their savings. Some of them have to borrow money from relatives or friends. Hence, when incomes quickly shrank due to COVID-19, older migrant couples tended to face serious challenges, which increased their sense of stress.

"My daughter graduated from a vocational school in Nanjing. Now she works in a cake shop and lives with us. She has a low salary, so I often give her some money to buy 
clothes and cosmetics...Due to the virus, I think we will have no savings this year." (Mrs. Fang, gatekeeper, age 44)

"For my son's wedding, I purchased a car and an apartment in the county. Thus, I have a debt of 200 thousand RMB.... I feel quite stressed because of the salary reduction...I want to increase my earnings, but I have no means to do so." (Mrs. Jia, hourly maid, age 51)

Lacking means to increase earnings and holding financial burdens, older migrant couples are inclined to adopt some passive strategies to deal with difficulties. For instance, most of the older participants mentioned that they greatly reduced household expenses to maintain a basic standard of living. Meanwhile, their adult children living with them also learned to control their expenses. Another strategy is to return to the hometown. Many of the older migrant respondents have lived in their current cities for a long period. They also have purchased housing in towns or counties near the hometown, or retain old housing in home villages. Although most of them are now more familiar with their urban lives and their children tend to stay in the cities, returning to the hometown remains a last-ditch option for them to escape financial pressures. They can normally earn only a little in the hometown, but they can live a simpler life without the high living costs of the city.

"My wife now controls the household expenses and we don't buy meat often...My son lived with us...I sometimes tell my son that your dad has no salary. He understands this and reduces his spending....... may return to my hometown because of my economic circumstances. Probably, living in the village will be less convenient than living in Nanjing, but I don't care. The living cost is quite low there."

(Mr. Chen, decoration worker, age 55)

In addition to reducing expenses or even planning to return to home villages, older migrant couples assisted their children and accepted help from their children in times of difficulty. We found that when senior rural migrants faced challenges related to COVID-19, they perceived the roles of children in a variety of ways. First, for families with only one (adult) child, the parents provided assistance to their child and did not ask for help in return. Second, those who had sons and daughters had different notions of different children during the period of COVID-19 spread. Some of these respondents mentioned that they asked their sons to save their wages, but they accepted daughters' money if they were having difficulty.

"My son and his wife now live with us and we cover their living costs; he needs to save money to feed his family.... When my son got married, my daughter used her savings to help him. If we are in serious difficulty, I think she will also give me her money." (Mrs. Jia, hourly maid, age 51)

"My son lives with us. He saves his salary because he needs to prepare for his future. If he can't afford an apartment, I think no girl will marry him." (Mr. Chen, decoration worker, age 55)

The coping strategies of senior migrant couples were derived from their traditional patricentric thinking, particularly the notion that a son will become the head of the family in the future and have the responsibility to care for the parents in their old age. Hence, based on reciprocal logic, the parents tend to concentrate all their efforts on supporting their sons and expect that their sons, rather than their daughters, will care for them in the future.

\section{Conclusion}

The COVID-19 pandemic has changed the lives of many people around the world and its impacts have varied among people with different socioeconomic backgrounds. Normally, disadvantaged people are more likely to suffer from a disaster and to bear tremendous negative social impacts. Hence, two important questions are raised concerning disadvantaged people in the context of COVID-19: which social impacts they faced and which strategies they adopted to cope with difficulties. In China, rural migrants are disadvantaged in cities because of institutional barriers and inequalities in education, welfare, and social capital (Song et al., 2008; Yue et al., 2013). They are known to rely on kinship networks and most of them subscribe to the family values embedded in traditional Chinese culture. Through face-to-face interviews, this paper investigates social impacts on rural migrants resulting from the spread of COVID-19 and their coping strategies during this period. It offers an empirical picture of the differentiated experiences of disadvantaged people at different stages of the life cycle in the context of a disaster. This paper not only extends relevant theories by focusing on rural migrants in the Chinese setting, but also provides insights into coping mechanisms from a household perspective.

The findings show that rural migrants suffered seriously from the COVID-19 pandemic, no matter which life-cycle stage they were at. Urban labor markets are highly segregated such that rural migrants normally undertake low-end manual jobs in cities, such as waiter, shop assistant, or factory worker (Chan et al., 1999). Unlike many white-collar workers, they typically cannot make a living working online while they are trapped at home. They have to be present at their working places, which was prevented by movement controls implemented to reduce the spread of COVID-19. This gave rise to great challenges in connection with their employment and income. In addition, rural migrants tend to be employed in informal or private workplaces that rarely guarantee basic social insurance (Wang, 2011). At the same time, rural migrants are neither local urban residents nor villagers below the poverty level, so they are largely ignored by governments. As a consequence, due to the spread of COVID-19, rural migrants pervasively encountered difficulties such as sharp reductions in income and job loss, but were largely ineligible for support from employers and governments.

Despite facing some similar challenges, the social impacts of COVID-19 varied among rural migrants at different stages of the life cycle, due to variations in human capital, family burdens, role in the household, and ability to find part-time work. In relation to their position in the life course, single rural migrants tend to suffer from shrinking incomes, job loss, living instability and delayed ability to pay loans. Despite having no family burdens, this group of rural migrants is more likely to be trapped in unstable working and living conditions in cities due to limited human capital, work experience, and social resources. A sudden disaster heightens the precarity of their situations in cities. Younger migrant couples usually bear heavy family burdens. They have to shoulder familial responsibilities and while they struggle for a better life in cities. As a result of COVID-19, their long-term household plans were modified or delayed. The ideal of settling down and becoming true citizens in cities became less attainable for them. Influenced by traditional culture, older migrant couples still take responsibility for their children (especially their sons), thereby transferring some financial burdens to the older generation. However, without useful sources of information to find part-time jobs, these older parents were more likely than their adult children to fall into financial difficulties during the period of COVID-19 spread, had to control their living costs strictly, and in some cases had to return to home villages. Despite working and living in cities for a long period, they are still 
marginal people in cities, floating between urban areas and their rural hometowns. Overall, it is apparent that these disadvantaged people at all life cycle stages fell into a more vulnerable situation in cities during the spread of COVID-19.

In urban China, rural migrants normally have limited interactions with local urban residents. In addition, upward social mobility is quite low among rural migrants with humble backgrounds (Unger and Siu, 2019). Therefore, compared to urban residents, who are covered by most social welfare systems when facing crises such as the COVID-19 pandemic, rural migrants in China have to turn to kinship networks, which play a more crucial role in their urban lives. Previous studies found that household strategy is important to survival when disadvantaged people encounter difficulties. This study is consistent with prior findings that highlighted the importance of household strategy to disadvantaged people in difficult times. For rural migrants at different life-cycle stages, they have differentiated socioeconomic features; by adopting household strategies, they tried their best to cope with the threats induced by the spread of COVID-19. For single rural migrants, parents offer the safety of a "roof" in the home village, while siblings help when they encounter difficulties; meanwhile, single rural migrants provide emotional and instrumental support to their parents. In the homes of younger migrant couples, husbands seek part-time jobs outside, while wives stay at home to care for young children. Older parents also help to look after grandchildren and undertake domestic work, in order to ease the heavy burdens on younger migrant couples. As for the older migrant couples, they co-reside with or provide financial or instrumental support to their adult children; meanwhile, they receive understanding and practical help from children and spouses.

The stories of our participants display how the concept of "family as a unit" was constructed during the COVID-19 pandemic, particularly in the Chinese setting where family values embedded in Confucian ideology are emphasized. Despite the process of modernization and urbanization in China, traditional family values remain important, as highlighted by rural migrants during the COVID-19 spread in China. During the period, single rural migrants showed their filial piety and obedience to their parents and older siblings, and they received care and protection from these older family members. Among younger migrant couples, a clear gender arrangement was found within a household: husbands were the financial providers, whereas wives were responsible for domestic work and care for children at home. Older migrant couples expressed the notion that supporting their children was their obligation, even when they sacrificed their own benefits and obtained no material returns. In sum, when facing the COVID-19 pandemic, family members assist each other within a household, in the form of reciprocity and emotional support and with emphases on family cohesion and harmony. Based on the norms of the Confucian ideology, these values become critical to the constitution of family structure and the underlying rules that guarantee the proper functioning of a family unit. In this way, family members of rural migrants can work as a unit to maximize resources and reduce risks during the period of COVID-19 spread.

Receiving little support from government and employers, rural migrants in China have to adopt a household strategy as a means of survival when they cope with disaster. If governments want to reduce the burden of COVID-19 on disadvantaged households, they need to pay more attention to rural migrants, even though they are neither local urban residents nor actual rural residents. On the one hand, since the major impact of the COVID-19 pandemic on rural migrants is related to employment, governments need to make full use of public and private platforms to help rural migrants find jobs in difficult times. Training with knowledge and skills related to employment are also necessary for rural migrants to increase their capacity to find high-paying jobs. Additionally, the government should not only offer subsidies to local urban residents and villagers below the poverty level, but also take into account the so-called "floating population" in cities. Direct financial aid would be particularly helpful in enabling disadvantaged people to endure difficulties in cities. In the long term, the social security system for rural migrants should be further improved. It is necessary to expand the accessibility of basic social services, such as medical insurance, housing funds, and pensions to rural migrants, and to include rural migrants in the housing security system, in case they experience difficult times.

\section{Data availability}

The datasets generated during and/or analyzed during the current study are not publicly available due to confidentiality reasons, but are available in a codified form from the corresponding author on reasonable request.

Received: 1 August 2020; Accepted: 1 December 2020; Published online: 06 January 2021

\section{References}

Andrews G, Kearns R, Kontos P et al. (2006) Their finest hour: older people, oral histories, and the historical geography of social life. Soc Cult Geogr 7:153-177

Aptekar L (1990) A comparison of the bicoastal disasters of 1989. Behav Sci Res 24:73-104

Blaikie P, Cannon I, Wisner B (1994) At risk: natural hazards, people's vulnerability and disasters. Routledge, New York

Bolin R, Stanford L (1998) The northridge California earthquake: communitybased approaches to unmet recovery needs. Disasters 22:21-38

Bolton P, Liebow E, Olson J (1993) Community context and uncertainty following a damaging earthquake: low-income Latinos in Los Angeles, California. Environ Prof 15:240-247

Brodie M, Weltzien E, Altman W et al. (2006) Experiences of Hurricane Katrina evacuees in Houston shelters: implications for future planning. Am J Public Health 96:1402-1408

Cai F, Du Y (2011) Wage increases, wage convergence and the Lewis turning point in China. China Econ Rev 22:601-610

Cao Y, Chen X, Fan R (2011) Toward a Confucian family-oriented health care system for the future of China. J Med Philos 36:452-465

Chaganti S, Waddell J (2015) Employment change among Hurricane Katrina evacuees: impacts of race and place. J Public Manag Soc Policy 22:1-16

Chan KW, Buckingham W (2008) Is China abolishing the hukou system? China Q 195:582-606

Chan KW, Liu T, Yang Y (1999) Hukou and non-Hukou migrations in China: comparisons and contrasts. Int J Popul Geogr 5:425-448

Che L, Du H, Chan K (2020) Unequal pain: a sketch of the impact of the COVID19 pandemic on migrants' employment in China. Eurasian Geogr Econ. https://doi.org/10.1080/15387216.2020.1791726

Clifford R (1956) The Rio Grande flood. National Academy of Sciences-National Research Council, Washington

Cutter S, Boruff B, Shirley W (2003) Social vulnerablity to environmental hazards. Soc Sci Q 84:242-261

Dash N, Morrow B, Mainster J et al. (2007) Lasting effects of Hurricane Andrew on a working-class community. Nat Hazards Rev 8:13-21

Demurger S, Gurgand M, Li S et al. (2009) Migrants as second-class workers in urban China? A decomposition analysis. J Comp Econ 37:610-628

Durant T (2011) The utility of vulnerability and social capital theories in studying the impact of Hurricane Katrina on the elderly. J Fam Issues 32:1285-1302

Elliott J, Paris J (2006) Race, class, and Hurricane Katrina: social differences in human responses to disaster. Soc Sci Res 35:295-321

Fan C, Li T (2020) Split households, family migration and urban settlement: findings from China's 2015 national floating population survey. Soc Incl $8: 252-263$

Fan CC (2009) Flexible work, flexible household: labor migration and rural families in China. Res Sociol Work 19:377-408

Fei X (1983) Problem of providing for the senile in the changing family structure. J Peking Univ (Philos Soc Sci) 3:6-15

Fothergill A, Maestas E, Darlington J (1999) Race, ethnicity and disasters in the United States: a review of the literature. Disasters 23:156-173 
Gubhaju B, de Jong GF (2009) Individual versus household migration decision rules: gender and marital status differences in intentions to migrate in South Africa. Int Migration 47:31-55

Haas J, Kates R, Bowden M (1977) Reconstruction following a disaster. MIT Press, Cambridge

Huang Y, Guo F (2017) Welfare progeamme participation and the wellbeing of non-local rural migrants in metropolitan China: a social exclusion perspective. Soc Indic Res 132:63-85

Huang Y, Liang Z, Song Q et al. (2020) Family arrangements and children's education among migrants: a case study of China. Int J Urban Reg Res 44:484-504

International Labour Organization (2020) China: rapid assessment of the impact of COVID-19 on employment. Available via ILO. https://www.ilo.org/ emppolicy/areas/covid/WCMS_752056/lang--en/index.htm. Accessed 29 July 2020

Lee S (2015) Intimacy and family consent: a Confucian ideal. J Med Philos 40:418-436

Li B, Duda M (2010) Employers as landlords for rural-to-urban migrants in Chinese cities. Environ Urban 22:13-31

Li S (2010) The economic situation of rural migrant workers in China. China Perspect 4:4-15

Lu P, Zhou T (2008) Housing for rural migrant workers: consumption characteristics and supply policy. Urban Policy Res 26:297-308

Marchetti S, Venturini A (2013) Mothers and grandmothers on the move: labour mobility and the household strategies of Moldovan and Ukrainian migrant women in Italy. Int Migration 52:111-126

Masozera M, Bailey M, Kerchner C (2007) Distribution of impacts of natural disasters across income groups: a case study of New Orleans. Ecol Econ 63:299-306

Mberu B, Ezeh A, Chepngeno-Langat G et al. (2013) Family ties and urban-rural linkages among older migrants in Nairobi informal settlements. Popul Space Place 19:275-293

Messias D, Barrington C, Lacy E (2012) Latino social network dynamics and the Hurricane Katrina disaster. Disasters 36:101-121

Mingione E (1994) Life strategies and social economics in the postfordist age. Int J Urban Reg Res 18:24-45

Morrow B (1999) Identifying and mapping community vulnerability. Disasters 23:1-18

National Bureau of Statistics of the People's Republic of China. (2020) Statistical bulletin of the People's Republic of China on the 2019 National Economic and Social Development. National Bureau of Statistics of the People's Republic of China

Pahl R (1984) Divisions of labour. Basil Blackwell, New York

Pais J, Elliott J (2008) Places as recovery machines: vulnerability and neighborhood change after major hurricanes. Soc Forces 84:1415-1453

Peacock W, Morrow B, Gladwin H (1997) Hurricane Andrew: ethnicity, gender, and the sociology of disasters. Routledge, New York

Pratt G, Hanson S (1991) On the links between home and work: family household strategies in buoyant labor market. Int J Urban Reg Res 15:55-74

Qi X (2018) Floating grandparents: rethinking family obligation and intergenerational support. Int Sociol 33:761-777

Qian W, Li B (2013) Consumption determinants of migrant workers from the uncertainty perspective: based on a national survey in China. Chin Rural Econ 11:51-71

Qin M, Zhuang Y, Liu H (2015) Old age insurance participation among rural-urban migrants in China. Demogr Res 33:1047-1066

Rahman S (2020) Social distancing during COVID-19: the metaphors and politics of pandemic response in India. Health Sociol Rev 29:131-139

Ray M (2018) Crossing borders: family migration strategies and routes from Burma to the US. J Ethinc Migration Stud 44:773-791

Richards P, Amara J, Ferme M et al. (2015) Social pathways for Ebola virus disase in rural Sierra Leone and some implications for containment. PLoS Negl Trop Dis 9:e0003567

Ryan L (2004) Family matters: (e)migration, familial networks and Irish women in Britain. Sociol Rev 52:351-370

Ryan L, Sales R (2013) Family migration: the role of children and education in family decision-making strategies of Polish migrants in London. Int Migration 51:90-103

Ryan L, Sales R, Tilki M et al. (2009) Family strategies and transnational migration: recent Polish migrants in London. J Ethinc Migration Stud 35:61-77

Sacchetto D, Vianello F (2015) Unemployed migrants coping with the economic crisis: Romanians and Moroccans in Italy. J Int Migration Integr 17:839-852

Sastry S, Dutta M (2017) Health communication in the time of Ebola: a culturecentered interrogation. J Health Commun 22:10-14
Song Y, Zenou Y, Ding C (2008) Let's not throw the baby out with the bath water: the role of urban villages in housing rural migrants in China. Urban Stud 45:313-330

Stanturf J, Goodrick S, Warren M et al. (2015) Social vulberability and Ebola virus disease in rural Liberia. PLoS ONE 10:e0137208

Stark O (1991) The migration of labor. Basil Blackwell, Cambridge

Stark O, Bloom DE (1985) The new economics of labor migration. Am Econ Rev 75:173-178

Tang S (2020) Determinants of migration and household member arrangement among poor rural households in China: the case of North Jiangsu. Popul Space Place 26:e2279

Tang S, Hao P, Feng J (2020) Consumer behavior of rural migrant workers in urban China. Cities 106:102856

Unger J, Siu K (2019) Chinese migrant factory workers across four decades: shifts in work conditions, urbanization and family strategies. Labor Hist 60:765-778

Wallace C (2002) Household strategies: their conceptual relevance and analytical scope in social research. Sociology 36:275-292

Wang YP, Murie A (2000) Social and spatial implications of housing reform in China. Int J Urban Reg Res 24:397-417

Wang Z (2011) Social security for China's migrant workers. Int Labour Rev 150:177-187

Wong KDF, Li CY, Song HX (2007) Rural migrant workers in urban China: living a marginalised life. Int J Soc Welf 16:32-40

Wong N, Ahuvia A (1998) Personal taste and family face: luxury consumption in Confusian and western societies. Psychol Mark 15:423-441

Wu W (2002) Migrant housing in urban China: choices and constraints. Urban Aff Rev 38:90-119

Yue Z, Li S, Jin X et al. (2013) The role of social networks in the integration of Chinese rural-urban migrants: a migrant-resident tie perspective. Urban Stud 50:1704-1723

Zhang L, Sharpe R, Li S et al. (2016) Wage differentials between urban and rural-urban migrant workers in China. China Econ Rev 41:222-233

Zhu P (2016) Residential segregation and employment outcomes of rural migran workers in China. Urban Stud 53:1635-1656

Zottarelli L (2008) Post-hurricane Katrina employment recovery: the interaction of race and place. Soc Sci Q 89:592-607

\section{Acknowledgements}

This research was supported by the National Natural Science Foundation of China [42071179]; Humanities and Social Sciences Foundation of Ministry of Education of the People's Republic of China under Grant [19YJCZH146]; Natural Science Foundation of Jiangsu Province [BK20190548]; National Natural Science Foundation of China [7191101210] and the Dutch Research Council [482.19.607].

\section{Competing interests}

The authors declare no competing interests.

\section{Additional information}

Correspondence and requests for materials should be addressed to X.L.

Reprints and permission information is available at http://www.nature.com/reprints

Publisher's note Springer Nature remains neutral with regard to jurisdictional claims in published maps and institutional affiliations.

Open Access This article is licensed under a Creative Commons Attribution 4.0 International License, which permits use, sharing, adaptation, distribution and reproduction in any medium or format, as long as you give appropriate credit to the original author(s) and the source, provide a link to the Creative Commons license, and indicate if changes were made. The images or other third party material in this article are included in the article's Creative Commons license, unless indicated otherwise in a credit line to the material. If material is not included in the article's Creative Commons license and your intended use is not permitted by statutory regulation or exceeds the permitted use, you will need to obtain permission directly from the copyright holder. To view a copy of this license, visit http://creativecommons.org/ licenses/by/4.0/.

(c) The Author(s) 2021 